\title{
Surgical management of a dermal lymphatic malformation of the lower extremity
}

\author{
Lisa F Schneider $M D^{1}$, Constance $M$ Chen MD MPH ${ }^{1}$, Joanna $M$ Zurada $M D^{2}$, \\ Robert Walther $\mathrm{MD}^{2}$, Robert T Grant $\mathrm{MD}^{1}$
}

LF Schneider, CM Chen, JM Zurada, R Walther, RT Grant. Surgical management of a dermal lymphatic malformation of the lower extremity. Can J Plast Surg 2008;16(4):236-238.

Dermal lymphatic malformations are rare congenital hamartomas of superficial lymphatics characterized by high recurrence rates after excision. The standard therapy for a single lesion is surgical excision with wide margins, which reduces recurrence but can have a potentially unacceptable aesthetic outcome. A case of a 24-year-old woman with a $6 \mathrm{~cm} \times 5 \mathrm{~cm}$ dermal lymphatic malformation on her right thigh, diagnosed by clinical history, physical examination, magnetic resonance imaging and pathological findings, is reported. The patient underwent wide local excision with splitthickness skin grafting. After pathological examination revealed negative margins, the patient underwent tissue expander placement and excision of the skin graft with primary closure. The lesion did not recur, and the patient achieved a satisfactory aesthetic result. The present case represents the first report of the use of tissue expanders to treat dermal lymphatic malformations in the lower extremity and demonstrates a safe, staged approach to successful treatment.

Key Words: Dermal lymphatic malformation; Lower extremity; Lymphangioma; Lymphangioma circumscriptum; Lymphatic malformation; Tissue expanders

\section{La prise en charge chirurgicale d'une malformation lymphatique dermique d'un membre inférieur}

Les malformations lymphatiques dermiques sont de rares hamartomes congénitaux des ganglions lymphatiques superficiels, caractérisées par un fort taux de récurrence après l'excision. Le traitement standard d'une simple lésion consiste à procéder à une excision chirurgicale à larges marges afin de réduire la récurrence, ce qui peut donner des résultats esthétiques inacceptables. Est exposé le cas d'une femme de 24 ans qui avait une malformation lymphatique dermique de $6 \mathrm{~cm}$ x $5 \mathrm{~cm}$ sur la cuisse droite, diagnostiquée grâce aux antécédents cliniques, à l'examen physique, à l'imagerie par résonance magnétique et aux résultats pathologiques. La patiente a subi une large excision localisée accompagnée d'une greffe de peau mince. Lorsque l'examen pathologique a révélé des marges négatives, la patiente a reçu un implant d'extension cutanée et subi l'excision de la greffe de peau lors de la fermeture primaire. La lésion ne s'est pas reformée, et la patiente a profité d'un résultat esthétique satisfaisant. Le présent cas est le premier rapport d'utilisation d'un implant d'extension cutanée pour traiter une malformation lymphatique dermique d'un membre inférieur et démontre une démarche sécuritaire en plusieurs temps pour réussir le traitement.

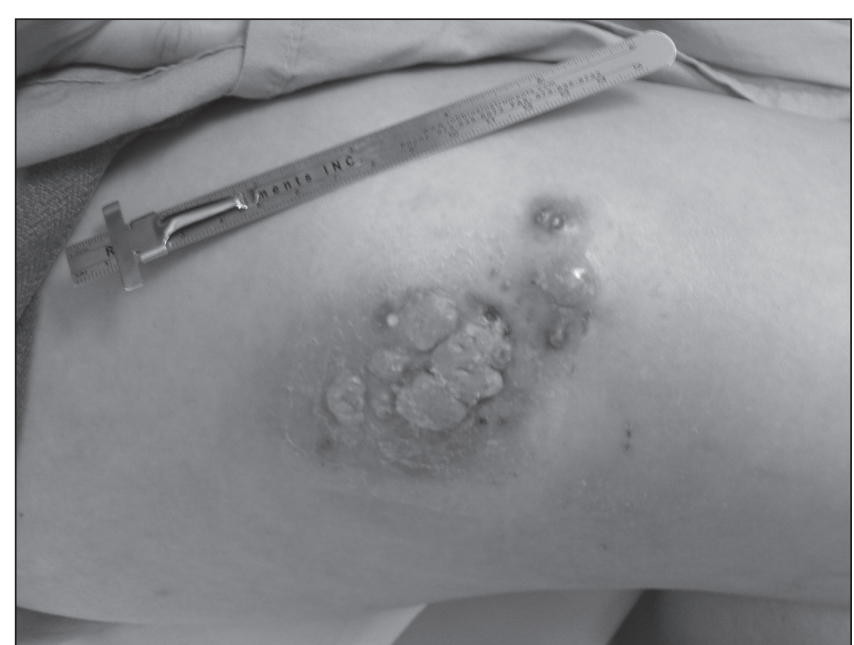

Figure 1) A $6 \mathrm{~cm} \times 5 \mathrm{~cm}$ area of dry, firm, rubbery nodules was seen on the right anterolateral thigh

image of the leg showed multiloculated inflamed cystic lesions in the subcutaneous tissue without evidence of vascular malformation or malignancy. The patient had no family history of vascular anomalies.

Under general anesthesia, wide local excision of the lesion was performed down to the deep fascia, creating a $15 \mathrm{~cm} \times 7 \mathrm{~cm}$ defect. A split-thickness skin graft was applied, which healed injections without visible improvement. A magnetic resonance

${ }^{1}$ Division of Plastic Surgery; ${ }^{2}$ Department of Dermatology, New York-Presbyterian Hospital, New York, New York, USA

Correspondence: Dr Robert T Grant, 161 Fort Washington Avenue, Suite 601, New York, New York 10032, USA. Telephone 212-305-3103,

fax 212-305-9348, e-mail rg424@columbia.edu 


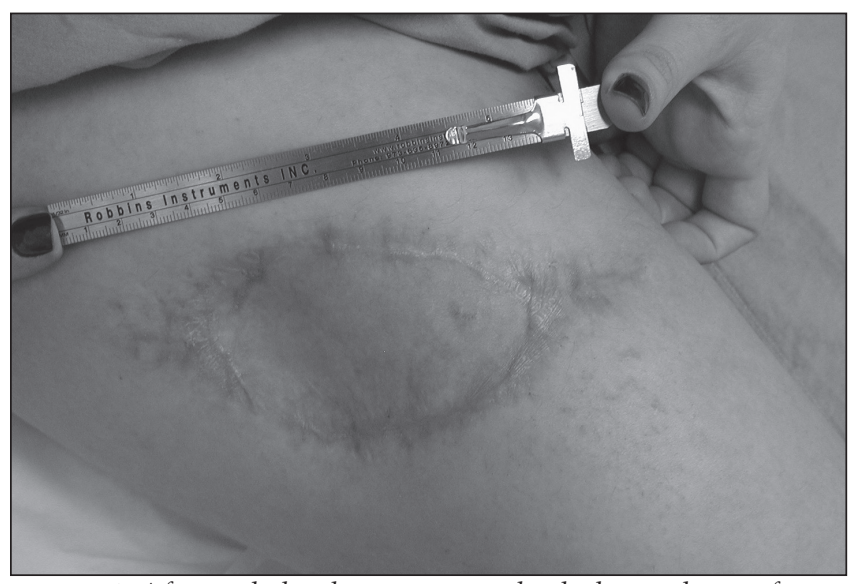

Figure 2) After wide local excision, a split-thickness skin graft was placed to cover the defect

without complications (Figure 2). Histopathological examination of the specimen revealed numerous follicular cystic structures and eccrine ducts with lymphocytes, plasma cells and scattered eosinophils. The findings were consistent with a diagnosis of a dermal lymphatic malformation. The surgical margins were clear of dermal lymphatic malformation.

Six months after the excision, tissue expanders were placed above the rectus femoris muscle on either side of the skin graft. Saline was injected over a period of seven weeks to reach a final volume of $170 \mathrm{~mL}$ per expander. One year after placement of the tissue expanders, the skin graft was excised and the adjacent tissue was advanced to close the defect, leaving only a linear scar (Figure 3). Eighteen months after the initial resection, there was no evidence of recurrence. After complete surgical excision and secondary reconstruction with local advancement flaps, the aesthetic result was satisfactory.

\section{DISCUSSION}

The pathologist Wegener first coined the term 'lymphangioma' in the 19th century to describe congenital malformations of the lymphatic system involving the skin and subcutaneous tissue (8). Because 'lymphangioma' may carry a false connotation of malignancy, 'lymphatic malformation' is the current preferred term for this disease $(8,9)$. Typically, lymphatic malformations are present at birth, but these lesions can spontaneously appear in adolescence or adulthood (9). There is no evidence for a familial basis for the disease and no potential for malignant transformation. Lymphatic malformations are surprisingly difficult to categorize because of the wide clinical and pathological spectrum of disease. The most widely accepted definition classifies lymphatic malformations into dermal and deep forms $(9,10)$.

Dermal lymphatic malformations (classically known as 'lymphangioma circumscriptum') appear anywhere on the skin and mucous membranes as grouped vesicles, which are superficial, clear and may be confused with warts (10). The dilated lymphatic vessels that create the lesion are located below the epidermis, most commonly in the papillary layer of dermis $(9,10)$. The resulting vesicles are usually asymptomatic but may bleed or release clear fluid after rupture. The lesions most often occur in multiple, relatively small (less than $1 \mathrm{~cm}^{2}$ ) groupings, and published reports of large dermal lymphatic malformations such as the one we describe are rare $(7,11,12)$.

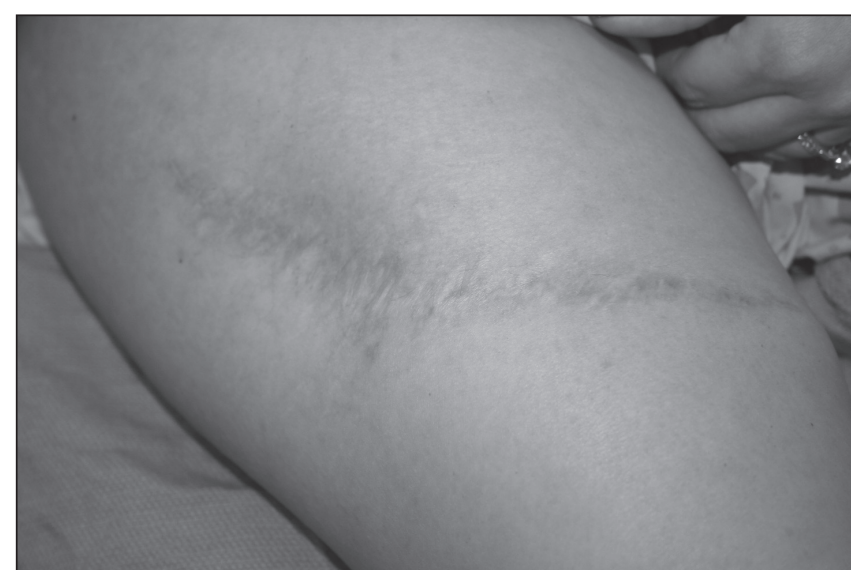

Figure 3) Eighteen months after initial resection of the lesion, the expanded tissue was advanced to close the defect and leave a linear scar

Dermal lymphatic malformations are distinct, both in morphology and in symptoms, from deep lymphatic malformations. Deep lymphatic malformations are often found in the extremities and are much more common than dermal lymphatic malformations. Deep lymphatic malformations lie beneath the dermis and do not have the same wart-like appearance as dermal lymphatic malformations. Deep lymphatic malformations may be divided into microcystic and macrocystic forms, also known by the outdated and imprecise terms 'cavernous lymphangioma' and 'cystic hygroma', respectively. This division into microcystic and macrocystic forms applies only to deep lymphatic malformations and not to dermal lymphatic malformations. Microcystic lymphatic malformations appear as a painless swelling in the skin and subcutaneous tissue (10). The overlying skin is unaffected, and the tissue beneath may feel spongy and similar in texture to a lipoma. With episodes of lymphangitis, affected areas may become more fibrotic. Macrocystic lymphatic malformations, which are associated with the greatest morbidity, are typically found in the cervical regions and may be associated with acute respiratory distress requiring emergency surgery (2). Macrocystic lymphatic malformations that present late in the first trimester and afterwards are associated with hydrops fetalis (9).

The diagnosis of dermal lymphatic malformation is made through a combination of history, physical examination, magnetic resonance imaging and light microscopy (9). Magnetic resonance imaging is used to define the depth of the lesion before surgery. All lymphatic malformations, including dermal forms, are visible on T2-weighted magnetic resonance imaging sequences because of the high water content. Anomalous, larger venous channels may also be demonstrated by imaging. Contrast is useful to enhance cystic lesions, especially when bleeding has occurred within. Although rarely performed, magnetic resonance lymphangiography may also be useful to visualize dilated or interrupted lymphatic channels (9). New markers are under investigation to improve pathological diagnosis. For example, Prox-1, a nuclear transcription factor key to embryonic lymphangiogenesis, differentiates the endothelial cells of lymphatic channels from blood vessels. Staining for Prox-1 may be useful to make a definitive diagnosis of lymphatic malformation, especially dermal forms (13).

Once the diagnosis has been made, many options have been tried to affect a cure. For small scattered foci of disease, numerous 
nonsurgical treatments have been attempted, with varying degrees of success. Steroid injections, such as triamcinolone, are classically ineffective. Other nonsurgical attempts to treat dermal lymphatic malformation include sclerotherapy (14), carbon dioxide laser ablation (15), pulsed-dye laser ablation (16) and radiotherapy (17). Complications of these therapies range from hyperpigmentation, transient swelling and erythema to ulcers, scarring, and recurrent or persistent disease.

Most surgeons recommend wide local excision as the standard of care for dermal lymphatic malformation. Even with surgery, recurrence rates range from $40 \%$ for incomplete excision to $17 \%$ to $25 \%$ for macroscopically complete excision $(9,10)$. In a series of 65 patients with dermal lymphatic malformation (11), there was a 75\% recurrence rate for lesions greater than $1 \mathrm{~cm}^{2}$. Nearly all recurrences were within 14 months of the initial resection, with 54\% recurring within three months (10). These recurrences may be persistent and difficult to eradicate (12).

The high recurrence rate is consistent with the pathophysiology of the disease. According to Whimster (1), lymphatic cisterns exist in the subcutaneous tissue down to the deep fascia. These cisterns are coated with muscle that contract and force lymphatic fluid toward the surface, leading to saccular dilations in the superficial dermal lymphatics that manifest as subcutaneous lymphatic vesicles. Thus, if the deep cisterns are not excised, the superficial vesicles will reappear. Wide resection, however, usually requires coverage with a skin graft $(9,12,18)$. To improve aesthetic result, suction-assisted lipectomy $(19)$ and flap reconstructions $(7,20)$ have been reported.

\section{REFERENCES}

1. Whimster IW. The pathology of lymphangioma circumscriptum. Br J Dermatol 1976;94:473-86.

2. Thomson H. Cutaneous hemangiomas and lymphangiomas. Clin Plast Surg 1987;14:341-56.

3. Vlastos AT, Malpica A, Follen M. Lymphangioma circumscriptum of the vulva: A review of the literature. Obstet Gynecol 2003;101:946-54.

4. Shah A, Meacock L, More B, et al. Lymphangioma of the penis: A rare anomaly. Pediatr Surg Int 2005;21:329-30.

5. Haas AF, Narurkar VA. Recalcitrant breast lymphangioma circumscriptum treated by UltraPulse carbon dioxide laser. Dermatol Surg 1998;24:893-5.

6. Mordehai J, Kurzbart E, Shinhar D, et al. Lymphangioma circumscriptum. Pediatr Surg Int 1998;13:208-10.

7. Kerst G, Niemeyer C, Hildebrandt F, et al. Use of a myocutaneous flap after resection of a large lymphangioma. Eur J Pediatr Surg 2001;11:139-41.

8. Wegener G. Ueber lymphangiome. Arch Klin Chir 1877;20:641-707.

9. Mulliken JB, Fishman SJ, Burrows PE. Vascular anomalies. Curr Probl Surg 2000;37:517-84.

10. Flanagan BP, Helwig EB. Cutaneous lymphangioma. Arch Dermatol 1977;113:24-30.

11. Peachey RD, Lim CC, Whimster IW. Lymphangioma of skin. A review of 65 cases. Br J Dermatol 1970;83:519-27.

12. Bauer BS, Kernahan DA, Hugo NE. Lymphangioma circumscriptum - a clinicopathological review. Ann Plast Surg 1981;7:318-26.
For large lesions, a staged reconstruction using a temporary skin graft followed by tissue expanders provides a means of complete excision, preventing recurrence with satisfactory aesthetic results. To our knowledge, the present report represents the first description of an unusually large lower extremity dermal lymphatic malformation that required tissue expanders for secondary reconstruction after wide local excision. The use of tissue expanders has been described to reconstruct vascular malformations in the head and neck of pediatric patients. The overall complication rate was $30 \%$, most commonly due to extrusion, infection or rupture, indicating the difficulty of the approach in this anatomic region in young patients (21). There is no previous report of the use of tissue expanders for the surgical management of a dermal lymphatic malformation in the extremities.

\section{CONCLUSION}

Dermal lymphatic malformation is an unusual entity. It is difficult to treat without recurrence and acceptable aesthetic results are often challenging to obtain. Nonsurgical therapy is usually inadequate, especially for large lesions. After confirming the diagnosis, a treatment plan consisting of wide local excision should be outlined. Due to the deep underlying nature of the disease, the affected skin and adjacent subcutaneous tissue must be removed down to the deep fascia to minimize recurrence. After resection, staged reconstruction using skin grafts and tissue expanders provides a simple, reliable technique to safely eliminate disease with satisfactory aesthetic results.

13. Reis RM, Reis-Filho JS, Longatto Filho A, et al. Differential Prox-1 and CD 31 expression in mucousae, cutaneous and soft tissue vascular lesions and tumors. Pathol Res Pract 2005;201:771-6.

14. Bikowski JB, Dumont AM. Lymphangioma circumscriptum: Treatment with hypertonic saline sclerotherapy. J Am Acad Dermatol 2005;53:442-4.

15. Huilgol SC, Neill S, Barlow RJ. CO(2) laser therapy of vulval lymphangiectasia and lymphangioma circumscriptum. Dermatol Surg 2002;28:575-7.

16. Lai CH, Hanson SG, Mallory SB. Lymphangioma circumscriptum treated with pulsed dye laser. Pediatr Dermatol 2001;18:509-10.

17. Lapidoth M, Ackerman L, Amitai DB, et al. Treatment of lymphangioma circumscriptum with combined radiofrequency current and $900 \mathrm{~nm}$ diode laser. Dermatol Surg 2006;32:790-4.

18. Jordan PR, Sanderson KV, Wilson JS. Surgical treatment of lymphangioma circumscriptum: A case report. Br J Plast Surg 1977;30:306-7.

19. Manders EK, Egan N, Davis TS. Elimination of lymphangioma circumscriptum by suction-assisted lipectomy. Ann Plast Surg 1986;16:532-4.

20. Latifoglu O, Yavuzer R, Demir Y, et al. Surgical management of penoscrotal lymphangioma circumscriptum. Plast Reconstr Surg 1999;103:175-8.

21. Hurvitz KA, Rosen H, Meara JG. Pediatric cervicofacial tissue expansion. Int J Pediatr Otorhinolaryngol 2005;69:1509-13. 